\title{
Assessment of radar interferometry performance for ground subsidence monitoring due to underground mining
}

\author{
Alex Hay-Man $\mathrm{Ng}^{1,2}$, Hsing-Chung Chang ${ }^{1,2}$, Linlin $\mathrm{Ge}^{1,2}$, Chris Rizos ${ }^{1,2}$, and Makoto Omura ${ }^{3}$ \\ ${ }^{1}$ Cooperative Research Centre for Spatial Information, 723 Swanston Street, Carlton VIC 3053, Australia \\ ${ }^{2}$ School of Surveying and Spatial Information Systems, The University of New South Wales, Sydney NSW 2052, Australia \\ ${ }^{3}$ Department of Environmental Science, Kochi Women's University, 5-15 Eikokuji-cho, Kochi 780-8515, Japan
}

(Received February 25, 2008; Revised August 12, 2008; Accepted November 2, 2008; Online published July 27, 2009)

\begin{abstract}
This paper describes the results from the recently launched SAR satellites for the purpose of subsidence monitoring over underground coal mine sites in the state of New South Wales, Australia, using differential interferometric synthetic aperture radar (DInSAR) technique. The quality of the mine subsidence monitoring results is mainly constrained by noise due to the spatial and temporal decorrelation between the interferometric pair and the phase discontinuities in the interferogram. This paper reports on the analysis of the impact of these two factors on the performance of DInSAR for monitoring ground deformation. Simulations were carried out prior to real data analyses. SAR data acquired using different operating frequencies, for example, X-, C- and L-band, from the TerraSAR-X, ERS-1/2, ENVISAT, JERS-1 and ALOS satellite missions, were examined. The simulation results showed that the new satellites ALOS, TerraSAR-X and COSMO-SkyMed perform much better than the satellites launched before 2006. ALOS and ENVISAT satellite SAR images with similar temporal coverage were searched for the test site. The ALOS PALSAR DInSAR results have been compared to DInSAR results obtained from ENVISAT ASAR data to investigate the performance of both satellites for ground subsidence monitoring. Strong phase discontinuities and decorrelation have been observed in almost all ENVISAT interferograms and hence it is not possible to generate the displacement maps without errors. However these problems are minimal in ALOS PALSAR interferograms due to its spatial resolution and longer wavelength. Hence ALOS PALSAR is preferred for ground subsidence monitoring in areas covered by vegetation and where there is a high rate ground deformation.
\end{abstract}

Key words: DInSAR, mine subsidence, ENVISAT, ALOS, interferometry, mining.

\section{Introduction}

Ground subsidence is the lowering or collapse of the land surface which can be caused by either natural or anthropogenic activities. Most ground subsidence in Australia is human induced, and in non-urban areas is usually related to underground mining, especially for coal. The magnitude (areal extent and amount) of subsidence due to underground mining depends on a number of factors, including the depth of cover, overlying strata properties, seam thickness, panel width, chain pillar size and surface topography (Nesbitt, 2003). The rocks above the mine workings may not have adequate support and can collapse from their own weight either during mining or long after mining has been completed. Therefore ground subsidence due to underground mining is a major concern to the mining industry, government, environmental groups and others (Ge et al., 2007). In Australia most underground coal mines employ the longwall mining technique, where a long 'wall' of coal is mined in a single slice in order to maximise the recovery of coal. The subsidence caused by this technique can be very large, occur immediately after or during mining, and can therefore damage infrastructure and public utilities, as well as

Copyright (c) The Society of Geomagnetism and Earth, Planetary and Space Sciences (SGEPSS); The Seismological Society of Japan; The Volcanological Society of Japan; The Geodetic Society of Japan; The Japanese Society for Planetary Sciences; TERRAPUB the environment. The subsidence induced by this mining technique can have a spatial extent of several hundred metres.

Several methods are currently used for mine subsidence monitoring, including levelling, total station surveys, and GPS (Schofield, 1993). However coverage of these techniques are limited as they measure subsidence on a pointby-point basis, requiring a dense network of ground survey marks in order to identify any regional-scale deformation induced by underground mining. Space-borne radar interferometry is a technique which can measure the ground movement (or deformation) that has taken place between the times of acquisition of the two radar images on a pixelby-pixel basis. It is therefore quicker, less labour intensive and less expensive compared to the conventional groundbased survey methods.

In the past, most space-borne SAR systems operated in C-band (with the exception of the Japanese JERS-1 satellite). Recently several new satellites with a variety of radar wavelengths have been launched. The aim of the study reported here is to investigate the performance of recently launched SAR satellites for subsidence monitoring over underground coalmine sites in the state of New South Wales, Australia, using the DInSAR technique. 


\section{Basic Theory}

Space-borne repeat-pass DInSAR has already proven its potential for ground deformation monitoring due to its high precision and high spatial resolution. DInSAR can observe ground displacement along the radar line-of-sight to an accuracy of a few millimetres. It has been used in applications such as monitoring volcanic activity (Lanari et al., 1998), determination of glacier movement (Goldstein et al., 1993), measuring earthquakes/seismic deformation (Massonnet and Feigl, 1995), monitoring underground mining activities (Ge et al., 2004, 2007) and urban subsidence (Chang et al., 2005).

Radar measures the amplitude (strength) and phase (time) of the microwave signals that are emitted by a radar antenna and reflected off a target on the ground. "Repeat pass" interferometry is a method which makes use of a single-antenna SAR system imaging an area by revisiting after a period of time. When the SAR system images the ground, both amplitude (strength) and phase (time) of the backscatters are recorded by the antenna. The amplitude indicates the target reflectivity, and the phase is related to the distance between the radar antenna to the target. Two SAR images acquired at different times can be combined to generate a radar interferogram, which includes the information about the (static) topography and any displacement in slant range direction that may have occurred between the two image acquisitions.

The simplified geometric configuration is shown in Fig. 1 where $S_{1}$ and $S_{2}$ are two radar antennas separated by the socalled "baseline distance" $B$. DInSAR make uses of the phase difference from two SAR images acquired over the same area. This phase difference is given by (Zebker et al., 1994; Hanssen, 2001):

$$
\Delta \phi=\frac{4 \pi}{\lambda} B \sin (\theta-\alpha)+\frac{4 \pi}{\lambda} \Delta R
$$

where $\theta$ is the look angle; $B$ is the baseline; $\alpha$ is the angle of the baseline vector measured from the orbital horizontal; $\lambda$ is the wavelength of the radar signal; and $\Delta R$ is the displacement that has occurred during two radar acquisitions along the line-of-sight if repeat-pass radar interferometry is performed.

The first term in Eq. (1) consists principally of two main components: 1) a spheroidal earth with no topography, and 2) the topography. The phase term due to the spheroidal earth with no topography is often referred to as the "flat earth phase" and is removed from the interferogram phase.

$$
\Delta \phi-\Delta \phi_{\text {flat }}=\frac{4 \pi}{\lambda} B \cos \left(\theta_{0}-\alpha\right) \frac{\Delta h}{R \sin \theta_{0}}+\frac{4 \pi}{\lambda} \Delta R
$$

where $\theta_{0}$ is the look angle to the reference surface; is the flat earth phase.

After the flat earth fringe is removed from the interferogram phase, the first term in Eq. (2) represents the topography and the second term indicates the displacement along the line-of-sight of the radar signal.

The phase shown in Eq. (2) is only for a simplified geometric configuration. In the case of real data analysis, the effect of atmospheric disturbances, orbit error and decorre-

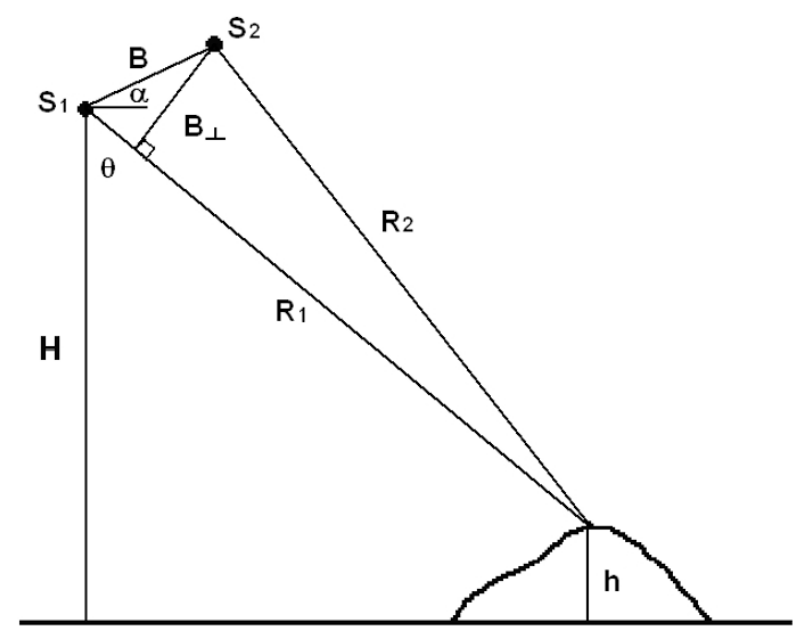

Fig. 1. InSAR geometry.

lation noise should also be considered. Hence, the interferometric phase can be written as:

$$
\Delta \phi=\phi_{\text {Topo }}+\phi_{\text {Defo }}+\phi_{\text {Atmos }}+\phi_{\text {Orbit }}+\phi_{\text {Noise }}
$$

where $\Delta \phi$ is the phase difference between the two images, $\phi_{\text {Topo }}$ is the phase due to the topography, $\phi_{\text {Defo }}$ is the phase due to the geometric displacement of the point, $\phi_{\text {Atmos }}$ is the phase due to atmospheric disturbances, $\phi_{\text {Orbit }}$ is the phase due to orbit error, and $\phi_{\text {Noise }}$ is the phase due to decorrelation noise.

The topographic phase $\phi_{\text {Topo }}$ and deformation phase $\phi_{\text {Defo }}$ can be expressed by (Nolan and Fatland, 2003):

$$
\begin{gathered}
\phi_{\text {Topo }}=\frac{4 \pi}{\lambda} B \cos \left(\theta_{\text {inc }}-\alpha\right) \frac{\Delta h}{R \sin \theta_{\text {inc }}}=\frac{4 \pi}{\lambda} \frac{\Delta h}{R \sin \theta_{\text {inc }}} B_{\perp} \\
\phi_{\text {Defo }}=\frac{4 \pi}{\lambda} \Delta R
\end{gathered}
$$

where $B_{\perp}$ is the perpendicular baseline separation between the satellites and $\theta_{\text {inc }}$ is the incidence angle.

It is possible to determine the deformation that has taken place between the two radar image acquisitions on a pixel-by-pixel basis by eliminating the other components in Eq. (3). In the results reported here, the topographic phase is carefully removed using a $25 \mathrm{~m}$ resolution external digital elevation model (DEM). The atmospheric disturbance is assumed to be insignificant as the spatial extent of the mine site area considered here is only of the order of several hundred metres (Carnec et al., 1996). The phase variation due to atmospheric heterogeneity is typically of the order of several kilometres. The orbit error contribution can be corrected during DInSAR analysis, and the phase noise can be reduced by applying an adaptive filter. What remains is the line-of-sight displacement that has occurred between two image acquisitions.

The accuracy of the deformation detection is often limited by the DEM errors. Accurate DEMs and small perpendicular baseline can reduce topographic noise and hence improve the accuracy of deformation detection. The effect of DEM vertical error on the uncertainty of DInSAR results 
can be determined by assuming that a signal-to-noise ratio of $0 \mathrm{~dB}$ is the minimum requirement to ensure valid interpretation. By equating $\phi_{\text {Topo }}$ to $\phi_{\text {Defo }}$ in Eqs. (4) and (5), the equation for measuring detectable deformation error in lineof-sight (LOS) direction due to DEM error can be derived (Nolan and Fatland, 2003):

$$
\Delta R=\frac{\Delta h}{R \sin \theta_{\text {inc }}} B_{\perp}
$$

Without SAR data from both ascending and descending orbit tracks, it is not possible to derive a 3-D deformation vector without making certain assumptions. The deformation due to underground mining activity is predominantly in the vertical direction, with the horizontal deformation being much smaller (Peng, 1986). The ground survey data measured using GPS at one of the test sites, Appin, of this paper shows a similar result. The GPS measurement suggests that at the centre of the long-wall panel the typical ground deformation in 35 days are $-450 \mathrm{~mm},-18 \mathrm{~mm}, 104 \mathrm{~mm}$ in vertical, easting and northing directions, respectively. Due to insufficient DInSAR results derived from various orbits and look angles, it is assumed in this paper that the horizontal deformation is negligible for the ease of calculation. Based on this assumption, the line-of-sight displacement can be converted into vertical displacement by:

$$
\Delta S=-\frac{\Delta R}{\cos \left(\theta_{\text {inc }}\right)}
$$

where $\Delta S$ is the surface displacement in the vertical direction.

Equations (5) and (7) suggest that the sensitivity of the radar for subsidence detection is dependent on the wavelength and the incident angle. The quality of ground subsidence monitoring using radar interferometry is mainly constrained by noise due to the spatial and temporal decorrelation between the interferometric pair and the phase discontinuities in the interferogram. In this study these two factors are used to analyse the performance of different satellites for monitoring ground deformation. The phase difference between any two adjacent pixels in the interferograms should be less than half a cycle in order to avoid aliasing during the phase-unwrapping process (Chen and Zebker, 2002). Therefore the maximum deformation of a whole subsidence bowl that can be detected without phase discontinuity can be written as:

$$
S_{\max , \mathrm{LOS}}=\frac{w}{g_{\text {resolution }}} \frac{\lambda}{4}
$$

where $S_{\max , \text { LOS }}$ is the maximum deformation of the subsidence bowl in the line-of-sight direction that can be detected without phase discontinuity, $g_{\text {resolution }}$ is the ground resolution of the SAR sensor, $w$ is the radius of the subsidence bowl and $\lambda / 4$ is the distance corresponding to a one-half cycle of the interferogram's phase. Assuming a subsidence bowl with radius $150 \mathrm{~m}$, theoretically the maximum deformation that can be detected (without phase discontinuity) is approximately $8 \mathrm{~cm}, 7 \mathrm{~cm}, 48 \mathrm{~cm}, 86 \mathrm{~cm}, 39 \mathrm{~cm}$ and $39 \mathrm{~cm}$ for the wavelengths of ERS, ENVISAT, JERS-1, ALOS, TerraSAR-X and COSMO-SkyMed satellites respectively, along the slant-range direction.

\section{Simulation}

Following the first radar mission SEASAT in 1978, subsequent space-borne radar missions had been dominated by the NASA space shuttles (http://www.jpl.nasa.gov/radar/sircxsar/) until the launch of ERS-1 by the European Space Agency (ESA) on 17 July 1991. Soon after the launch of ERS-1, the Japanese and Canadian space agencies launched JERS-1 and Radarsat-1, respectively. On 21 April 1995 ERS-2 was launched, allowing the ERS tandem mission to take place. Spaceborne radars were operated at two different bands between 1993 and 1998 (C-bands for ERS-1/2 and Radarsat-1, and L-band for JERS-1). However, there are several limitations for these satellites, such as low ground resolution and fixed look angle. There has been renewed interest among the European, Japanese, Italian and Canadian space agencies in the last few years. The ESA C-band satellite ENVISAT was launched in 2002 with varying look angle. Other recently launched satellites are the L-band ALOS, C-band Radarsat-2, and X-band satellites TerraSAR-X and COSMO-SkyMed-1 and 2. These provide high ground resolution as well as varying look angle capability. From Eqs. (5), (7) and (8), it can be seen that the maximum deformation of the whole subsidence bowl that can be detected depends on the incidence angle, wavelength and ground resolution. Therefore the feasibility of ground subsidence monitoring using radar interferometry can be greatly improved by SAR imaging with high ground resolution and varying look angle.

In the study reported in this paper, simulations were carried out prior to real data analyses in order to investigate the performance of different satellites under ideal conditions. SAR data with different operating frequen-

\begin{tabular}{|c|c|c|c|c|c|c|}
\hline Satellite & ERS & JERS-1 & ENVISAT & ALOS & TerraSAR-X & COSMO-SkyMed \\
\hline Sensor & AMI & SAR & ASAR & PALSAR & - & - \\
\hline Wavelength $(\mathrm{cm})$ & 5.67 & 23.53 & 5.62 & 23.61 & 3.1 & 3.1 \\
\hline Ground resolution (m) & 30 & 18 & 30 & 10 & 3 & 3 \\
\hline Altitude $(\mathrm{km})$ & 785 & 568 & 800 & 692 & 514 & 620 \\
\hline
\end{tabular}
cies, for example, X-, C- and L-band, from the TerraSAR-

Table 1. SAR satellite characteristics relevant to simulation studies.

* Relatively large incidence angle is chosen in this simulation for satellites that have variable incidence angle capability in order to increase the maximum detectable subsidence and minimise the subsidence error due to DEM error.

**ALOS PALSAR also has variable look angle capability with incidence angle range from $8^{\circ}-60^{\circ}$. However incidence angle of $38.7^{\circ}$ is chosen in this simulation to match with the real data used in this study. The simulation result will be different if different incidence angle is used. 


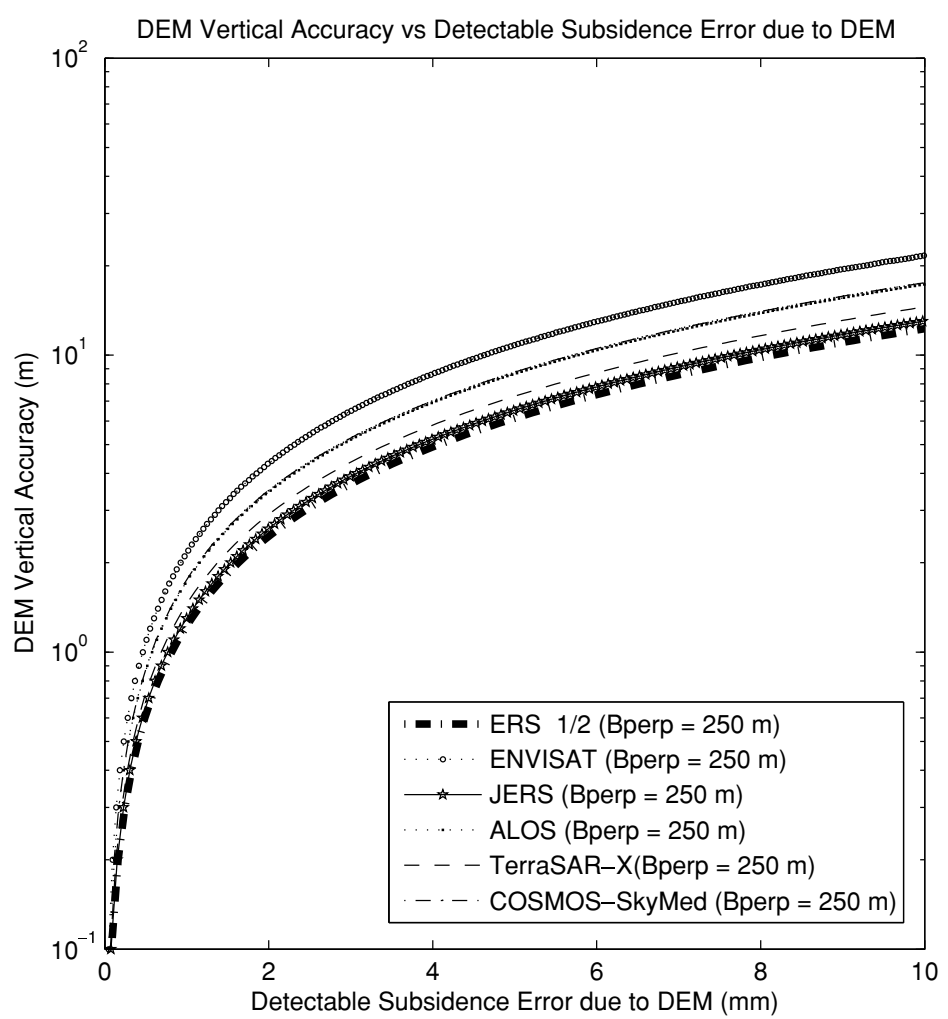

Fig. 2. DEM vertical accuracy versus detectable subsidence error for different satellites for an assumed perpendicular baseline $\left(B_{\text {perp }}\right)$ of $250 \mathrm{~m}$.

X, COSMO-SkyMed-1/2, ERS-1/2, ENVISAT, JERS-1 and ALOS satellites, have been considered. The basic characteristics of the satellites used in this study are listed in Table 1 .

\subsection{Effect of DEM errors}

Based on Eq. (6), it is possible to estimate the subsidence error due to the DEM uncertainty for different satellites. The relationship between DInSAR accuracy and DEM error is shown in Fig. 2, under the assumption of a perpendicular baseline of $250 \mathrm{~m}$. The LOS distance from satellite to ground is proportional to the altitude of the satellite; therefore the influence of DEM error is mainly dependent on the altitude of the satellite, incidence angle and the perpendicular baseline.

Figure 2 suggests that subsidence detected by ENVISAT is least affected by DEM error due to its high altitude and large incidence angle, followed by COSMO-SkyMed-1/2, ALOS, TerraSAR-X, JERS-1 and the C-band satellite ERS$1 / 2$. In addition to the vertical DEM accuracy, the horizontal resolution is another important factor impacting on the quality of DInSAR results. The residual topographic signal in the DInSAR result is expected to be much smaller when the DEM's horizontal resolution is finer than the ground resolution of the satellite image. This is due to higher coregistration accuracy between the master and DEM simulated image. Therefore, high resolution satellites such as TerraSAR$\mathrm{X}$ and COSMO-SkyMed require DEMs with much higher horizontal resolution. This is a concern because many commonly used DEMs do not have high enough resolution, and hence there is a reduction in vertical accuracy if they are used to remove the topographic phase from the TerraSAR$\mathrm{X}$ and COSMO-SkyMed interferogram.

\subsection{Assessment of radar interferometry performance with different peak subsidence}

3.2.1 Subsidence model used for simulation A subsidence model (Fig. 3) is derived using ALOS PALSAR DInSAR and is rescaled to 1 metre resolution for the simulation study. The model has a peak subsidence of $50 \mathrm{~cm}$. Differential interferograms are simulated based on the subsidence model using parameters of different satellites (Table 1), and are then converted into LOS displacement by unwrapping the differential interferogram phase.

3.2.2 Simulated interferogram The simulations have assumed both noise-free and noisy (noise level = $30^{\circ}$ in phase) conditions. The temporal and baseline decorrelation is not considered in the noise-free simulation. The noise level in the noisy simulation is assumed to be normally distributed with a standard deviation of $30^{\circ}$.

The subsidence model is rescaled based on the ground resolution of satellite and is converted into absolute phase using Eq. (7). The absolute phase is then wrapped to generate the differential interferograms (Figs. 4 and 5). The simulated differential interferograms from ERS and ENVISAT show the phase fringes in the interferogram representing the ground surface displacement are saturated. This is mainly due to the high phase gradient in the subsidence model. The maximum amplitude of subsidence using ERS and ENVISAT data is $9 \mathrm{~cm}$ and $10 \mathrm{~cm}$, respectively, which are much smaller than the peak subsidence $(50 \mathrm{~cm})$. In contrast, the phase fringes in the differential interferograms from ALOS, JERS-1, TerraSAR-X and COMOS-SkyMed data are reasonably clear.

The simulated interferogram phase is unwrapped using the MCF method (Costantini, 1998), and is then converted 


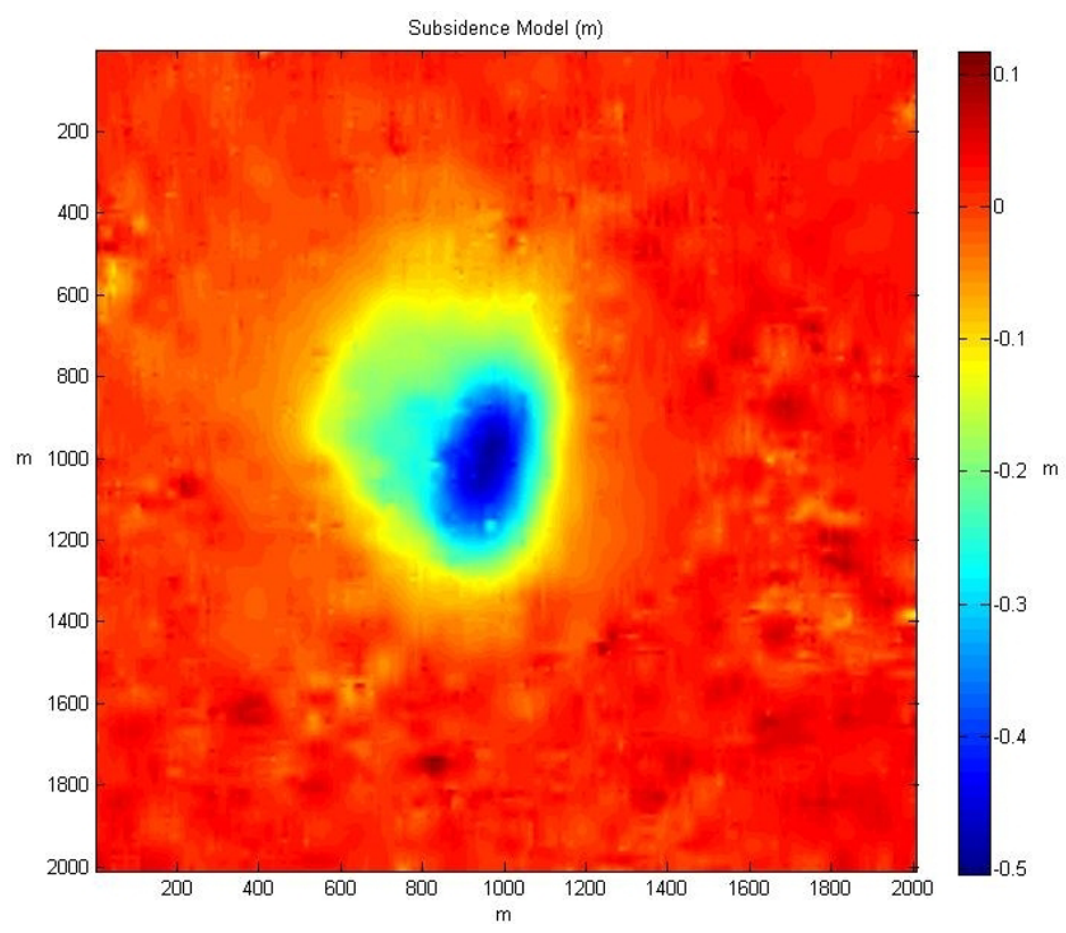

Fig. 3. Subsidence model derived from ALOS PALSAR DInSAR for simulation purposes.
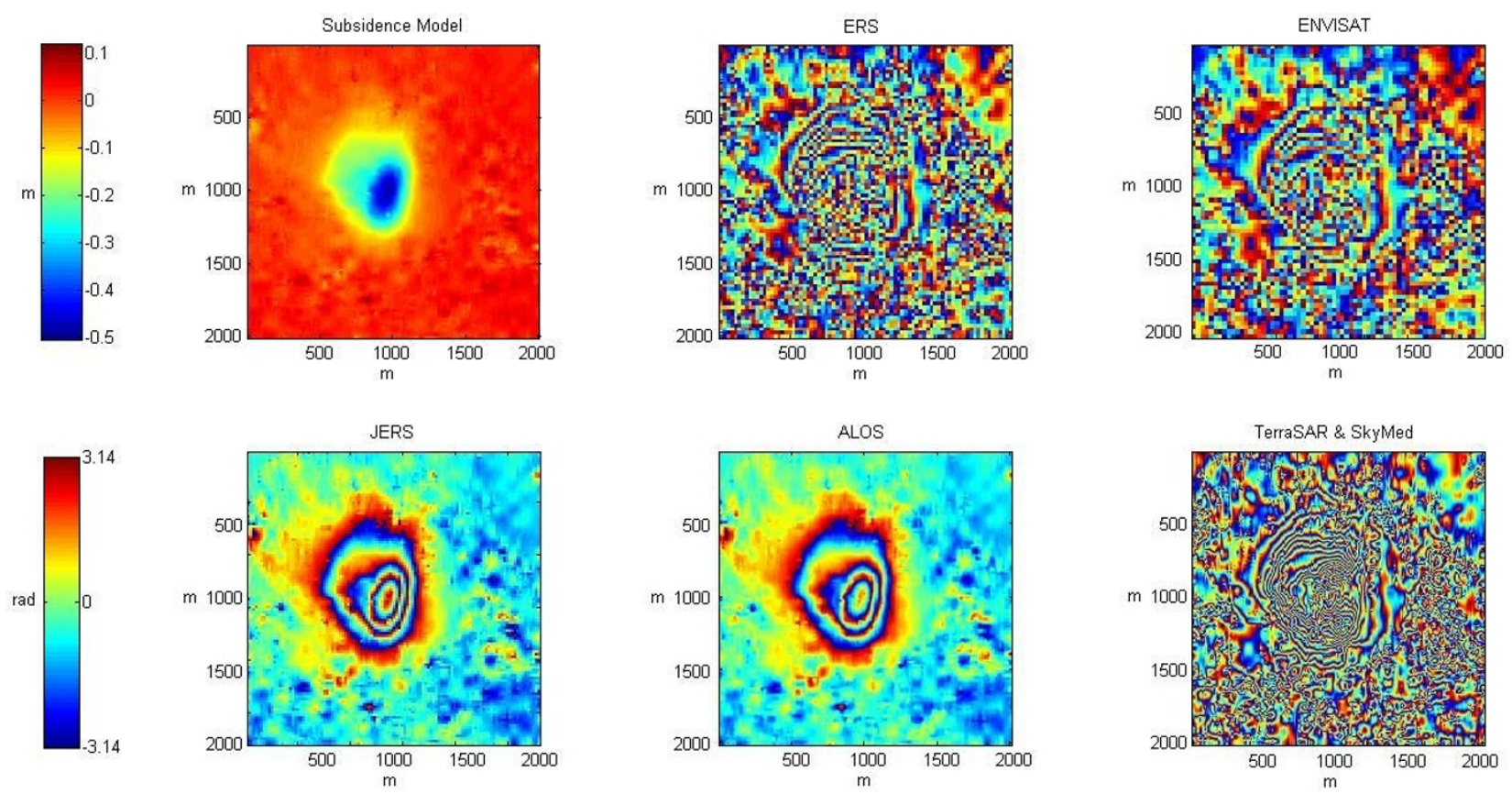

Fig. 4. Simulated differential interferograms from various SAR satellites based on the subsidence model under noise-free conditions. The displacement value in the subsidence model is indicated by the colour bar at upper left and the phase value in all the interferograms are indicated by the colour bar at lower left.

into vertical displacement (Figs. 6 and 7). The results clearly show that the subsidence map from ERS and ENVISAT give an incorrect result. Figure 8 shows the cross section of the subsidence maps under noise-free conditions. The maximum subsidence ERS and ENVISAT can detect from the subsidence model is about $8 \mathrm{~cm}$, which is much lower than the actual peak subsidence $(50 \mathrm{~cm})$. However, the phase from the other satellites is correctly unwrapped, and is accurate (when compared with the actual value).
3.2.3 Error analysis using subsidence model with different peak subsidence The original subsidence model (with peak subsidence of $50 \mathrm{~cm}$ ) was multiplied by a factor in order to investigate the displacement error for different magnitudes of peak subsidence. The Root Mean Square Error (RMSE) between the simulated displacement and actual displacement is used as an indication of the performance of different SAR satellites for different magnitudes of peak subsidence. The RMSE between two data 

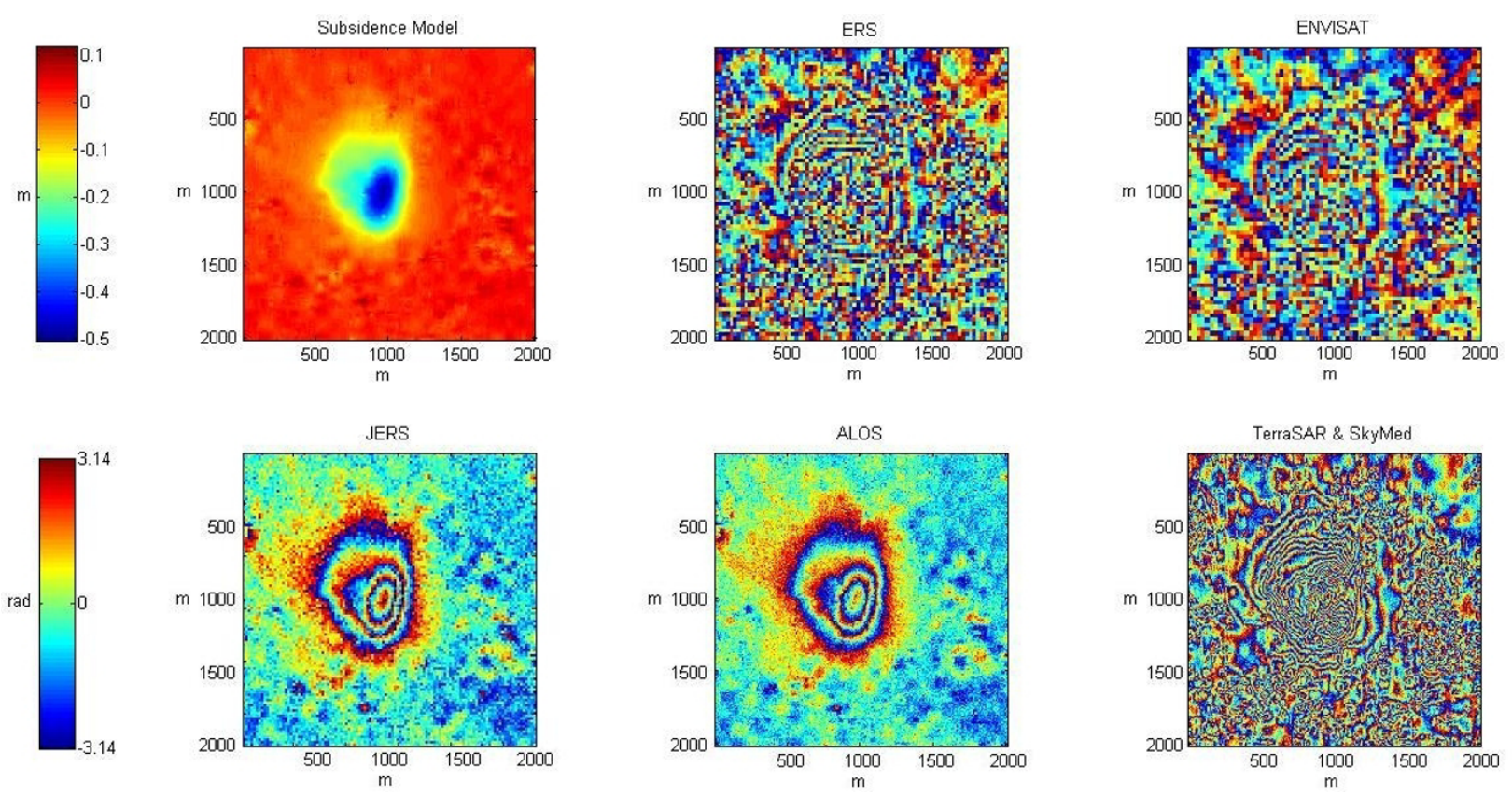

Fig. 5. Simulated differential interferograms from various SAR satellites based on the subsidence model with noise levels of $30^{\circ}$. The displacement value in the subsidence model is indicated by the colour bar at upper left and the phase value in all the interferograms are indicated by the colour bar at lower left.
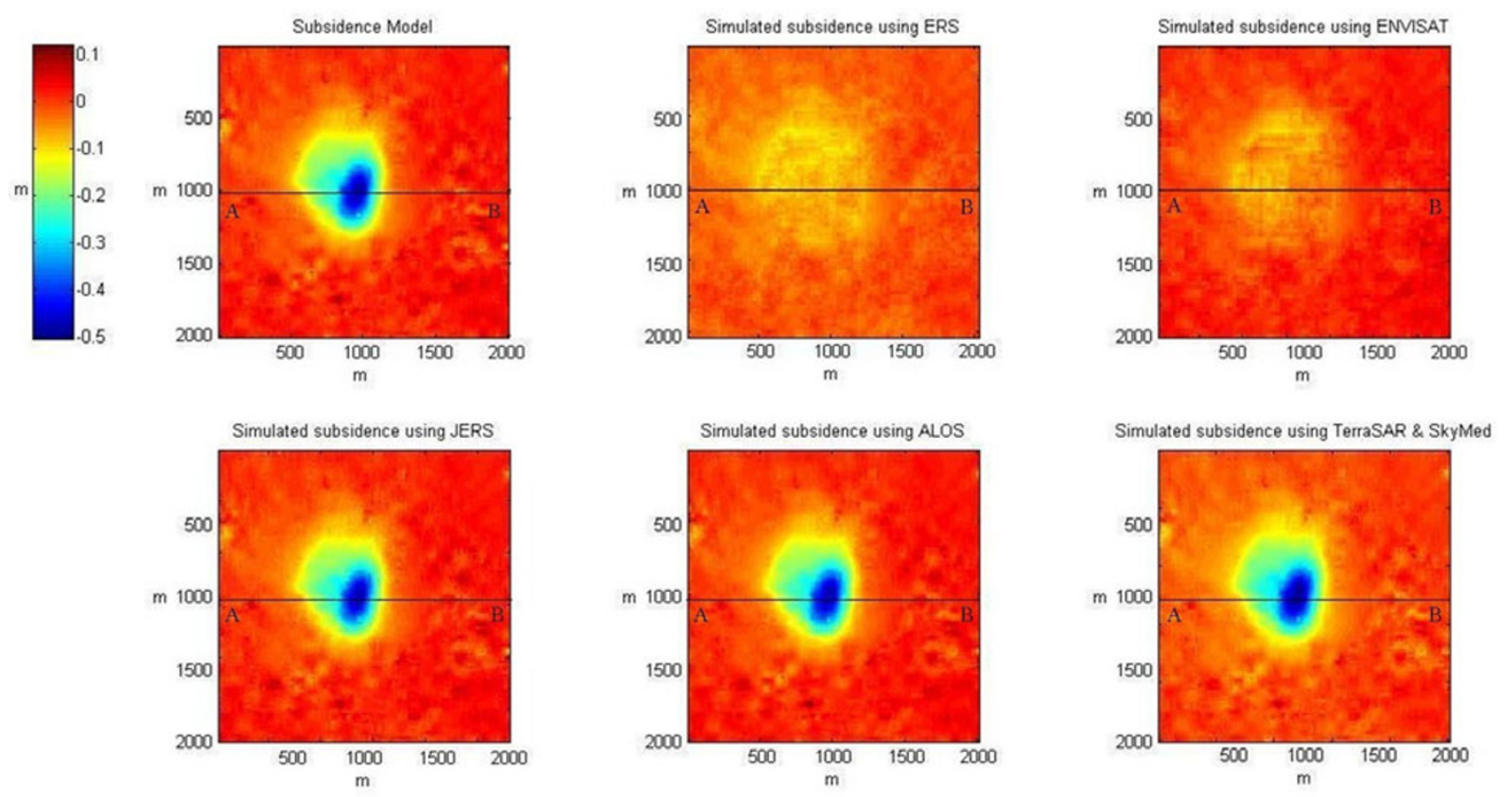

Fig. 6. Detectable subsidence under noise-free conditions.

sets can be calculated as:

$$
\mathrm{RMSE}=\sqrt{\frac{1}{l w} \sum_{l=1}^{L} \sum_{w=1}^{W}\left(S_{l w}^{(1)}-S_{l w}^{(2)}\right)^{2}}
$$

where $W$ is the width of the image by $w$ and $L$ is the length of the image by $l$.

Both noise-free and noisy conditions are considered in these simulations. The simulation for noisy conditions is repeated ten times for each subsidence model with different peak subsidence. The detectable subsidence errors with different peak subsidence under both conditions are shown in Figs. 9 and 10. Figure 9 shows that more recent satellites such as ALOS, TerraSAR-X and COSMO-SkyMed are able to measure the displacement with larger maximum detectable subsidence and lower detectable subsidence error. The L-band ALOS PALSAR is able to maintain a low subsidence error with relatively high maximum detectable subsidence. High RMSE is observed in ENVISAT and ERS for subsidence model with peak subsidence greater than $10 \mathrm{~cm}$, and the maximum detectable subsidence will be further reduced after noise is included. 

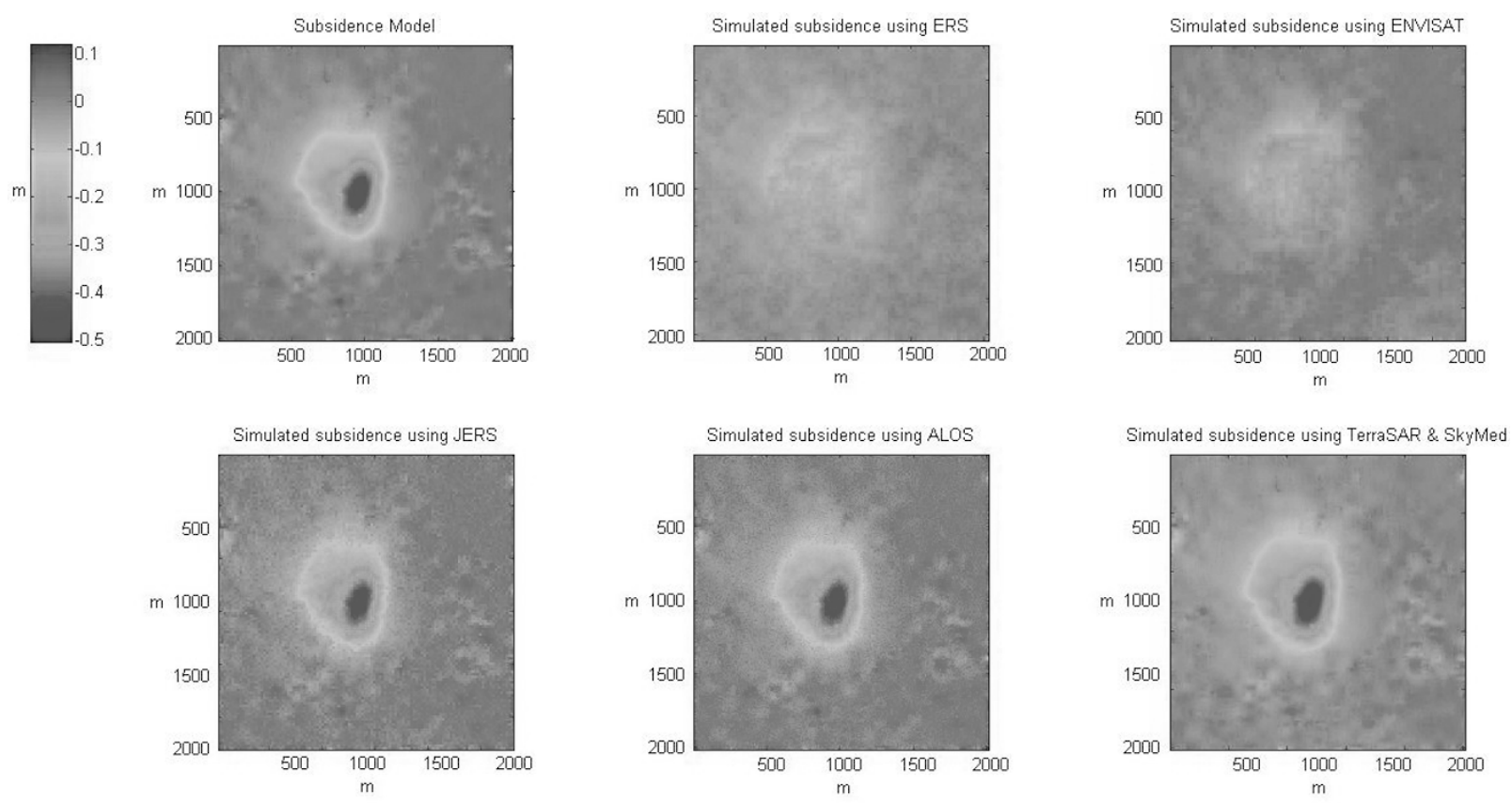

Fig. 7. Detectable subsidence under noisy conditions.

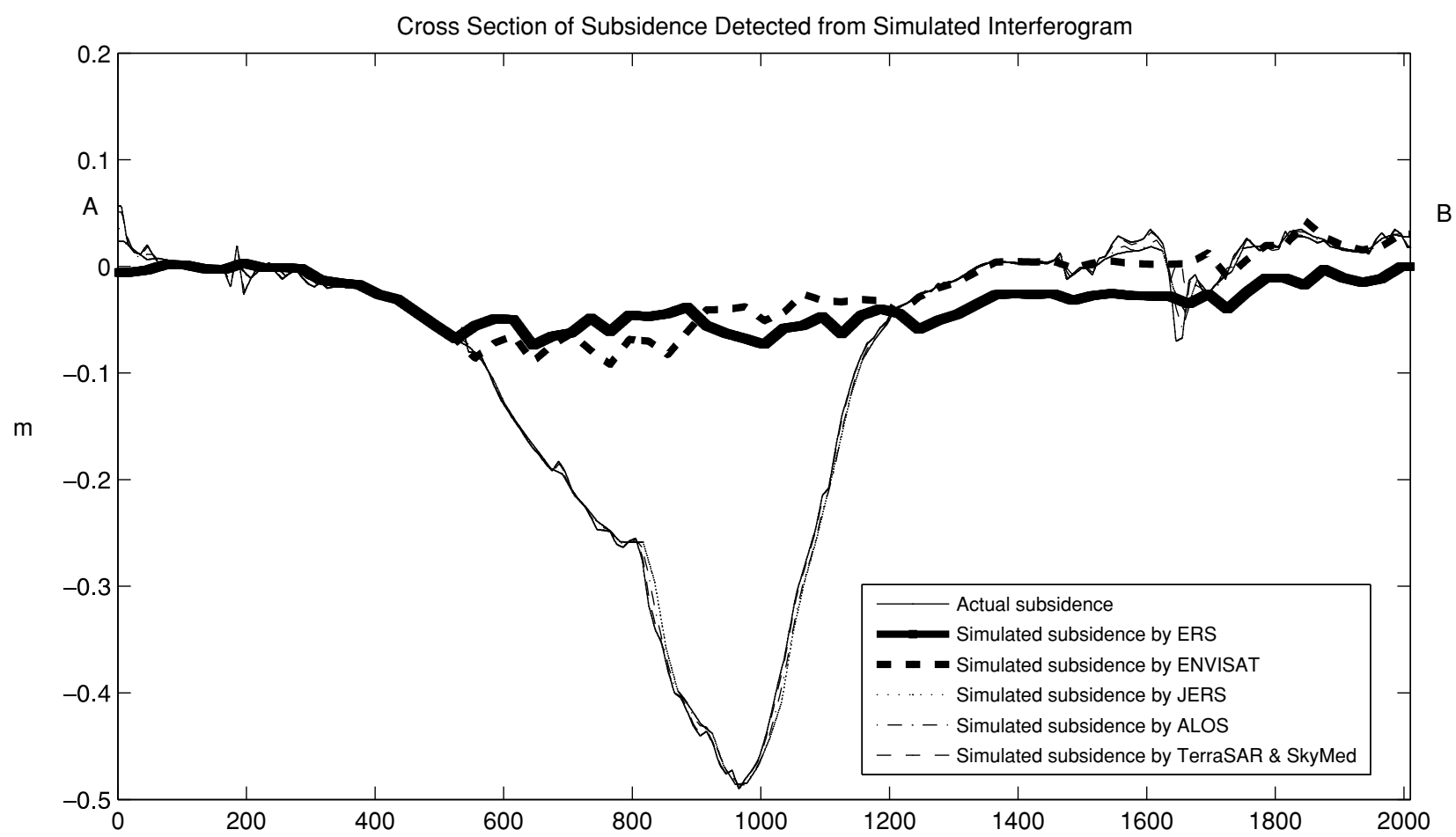

Fig. 8. Cross section of subsidence detected from the various simulated subsidence maps.

The simulated results show that the more recent satellites ALOS, TerraSAR-X and COSMO-SkyMed perform much better than older satellites for ground subsidence monitoring. X band satellites TerraSAR-X and COSMO-SkyMed have demonstrated their ability to monitor simulated ground subsidence in conditions where temporal decorrelation due to different terrain is not considered. The simulation result suggests that finer resolution and greater incidence angles can be used to overcome the high phase gradient.

\section{Test Sites}

The underground coalmines monitored in this study employ longwall mining techniques. The subsidence induced by this technique is expected to have a spatial extent of the order of several hundred metres. Two test sites were chosen for this study: (a) Tahmoor (Fig. 11), an underground mine located beneath an urban area, in order to investigate the performance of multi-platform satellites with respect to phase discontinuities; (b) Appin (Fig. 12), an underground mine site whose surface terrain is partially covered by veg- 


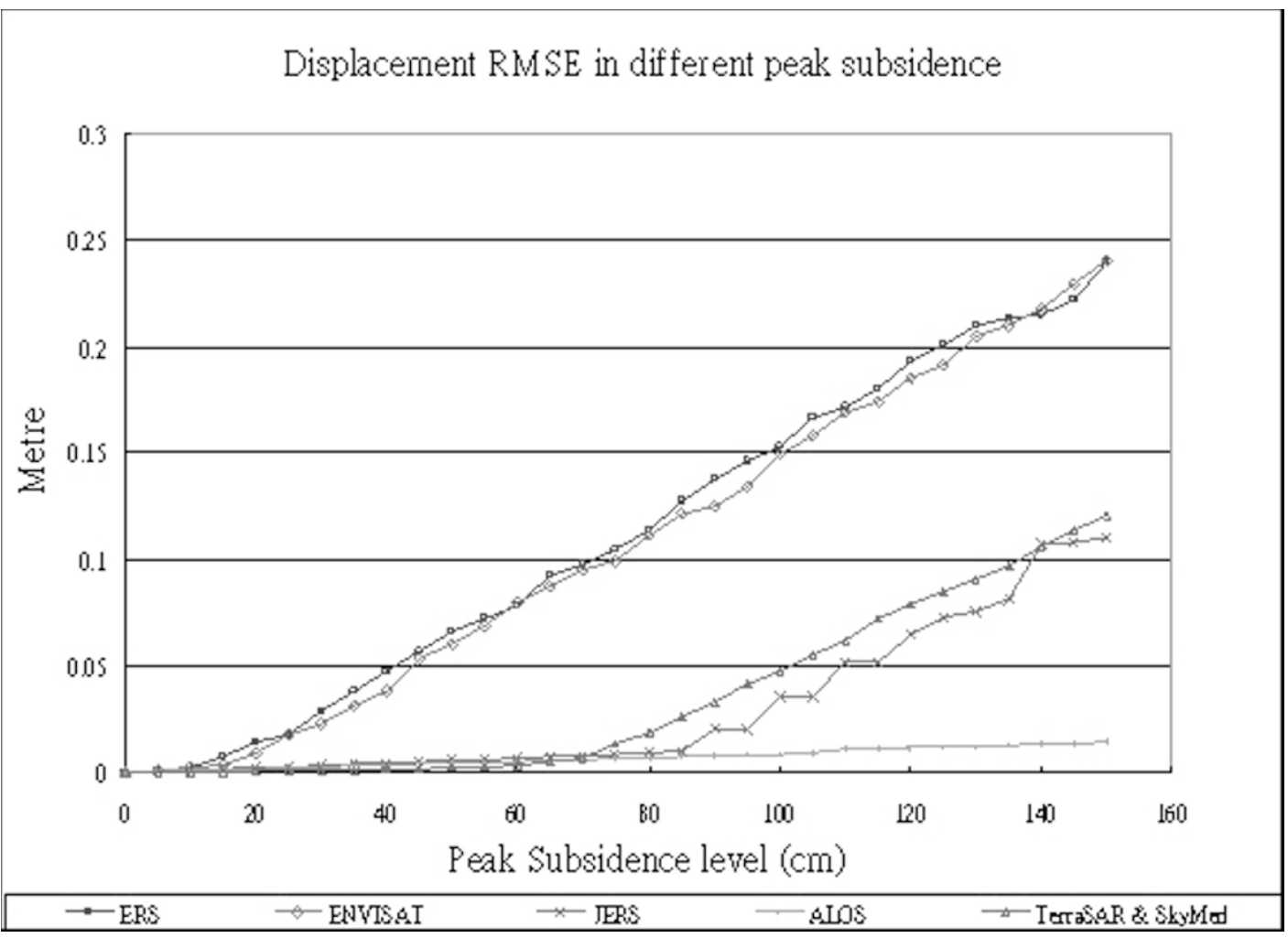

Fig. 9. Detectable subsidence errors with different magnitudes of peak subsidence under noise-free conditions.

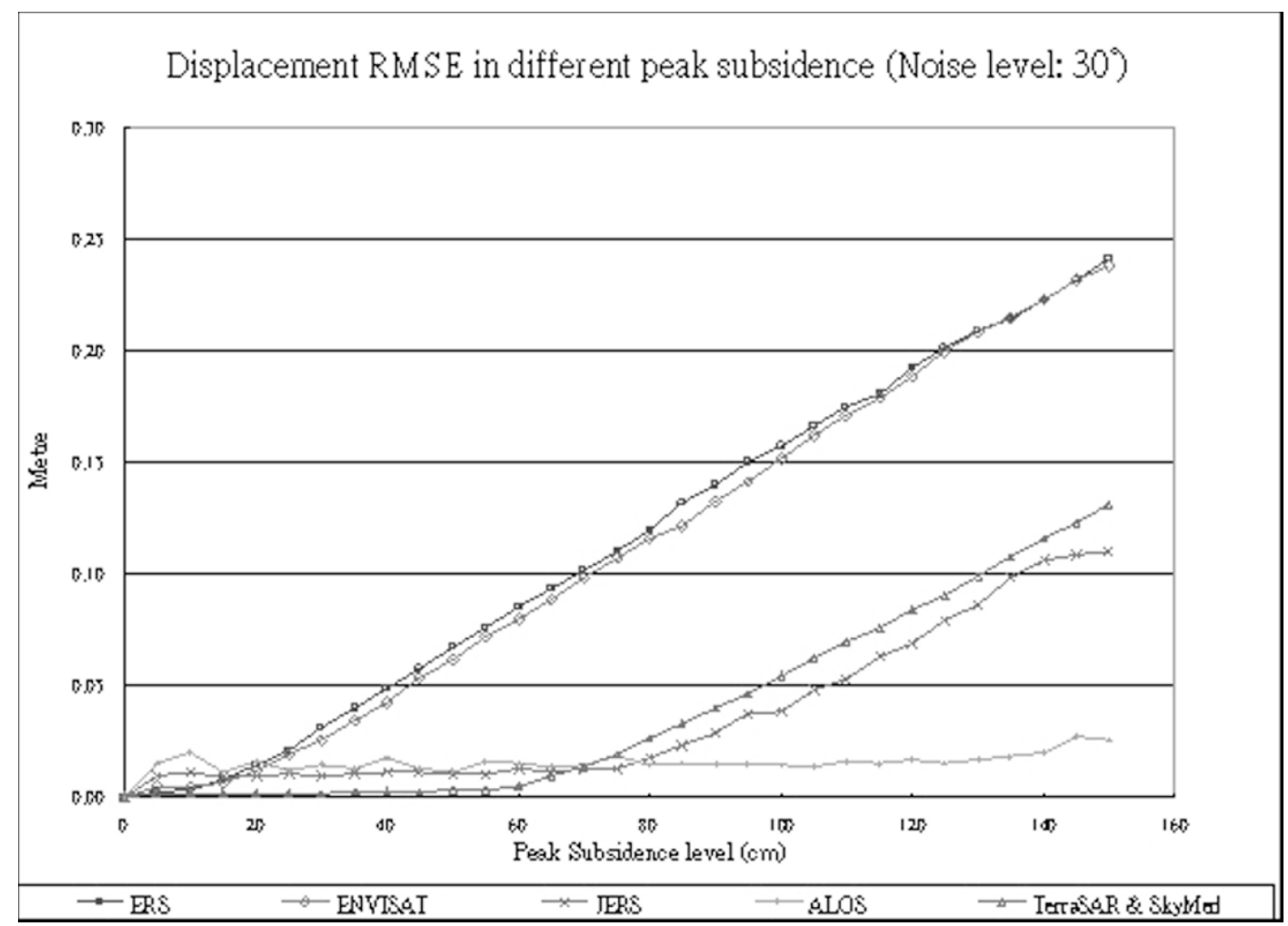

Fig. 10. Detectable subsidence errors with different magnitudes of peak subsidence under noisy conditions. 


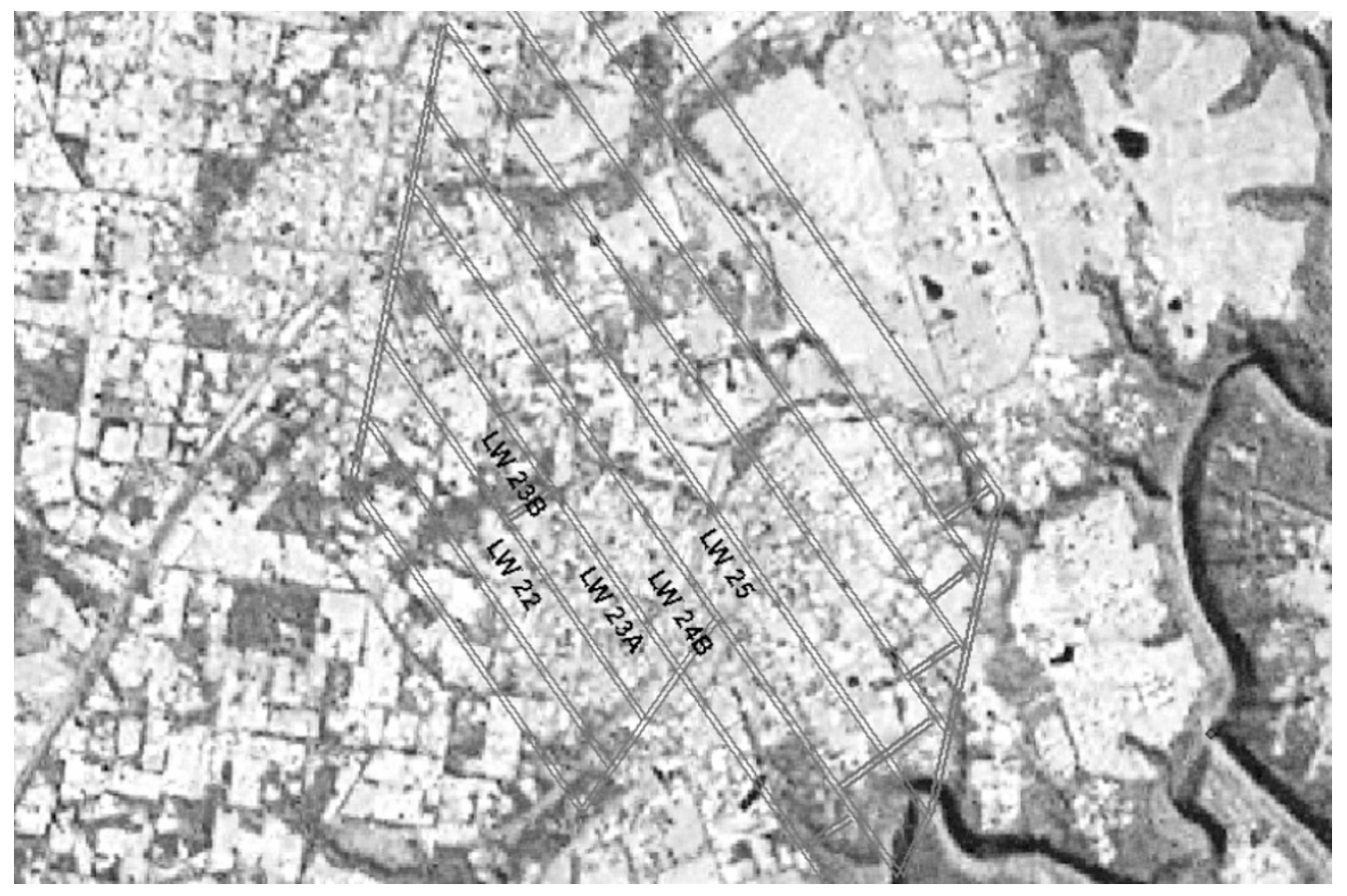

Fig. 11. Tahmoor Mine Site with longwall structure overlaid on the LANDSAT-7 images.

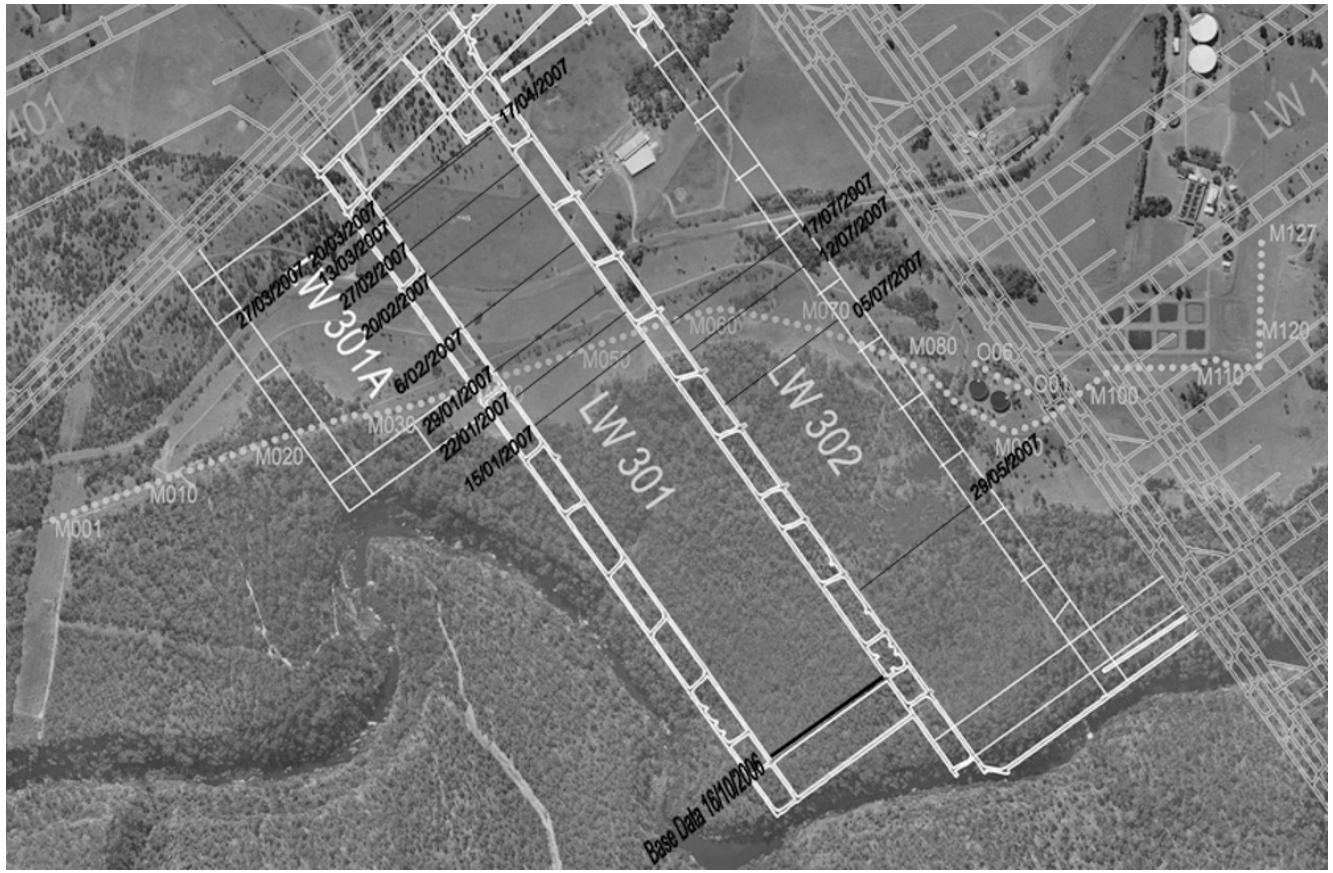

Fig. 12. Appin Mine Site (with longwall structure overlaid on an aerial photo). (C)BHP Billition)

etation, in order to investigate the effects of both temporal decorrelation and phase discontinuities.

The width of each longwall panel in the underground mines is about $300 \mathrm{~m}$, which is $150 \mathrm{~m}$ from the edge to the centre of a longwall panel (GeoTerra, 2006). The depth of the coalmines in the test sites is between $420 \mathrm{~m}$ and $480 \mathrm{~m}$ (GeoTerra, 2006). The mine subsidence at the test sites have typical peak amplitudes of 20 to $50 \mathrm{~cm}$, and even greater during the period 1-2 months after the mine process has ceased, and can be up to $90-100 \mathrm{~cm}$ over a full year.

As the peak subsidence at the mine site is much greater than the maximum subsidence that SAR on ERS and ENVISAT can detect, the phase fringes in the ERS and ENVISAT interferogram corresponding to the ground surface displacement are expected to be saturated.

\section{Spaceborne SAR Data}

Real C-band ENVISAT ASAR and L-band ALOS PALSAR data were used to determine ground deformation. The performances of past satellites such as ERS-1/2 and JERS1 for mine subsidence monitoring have already been discussed in a previous study (Ge et al., 2007). 

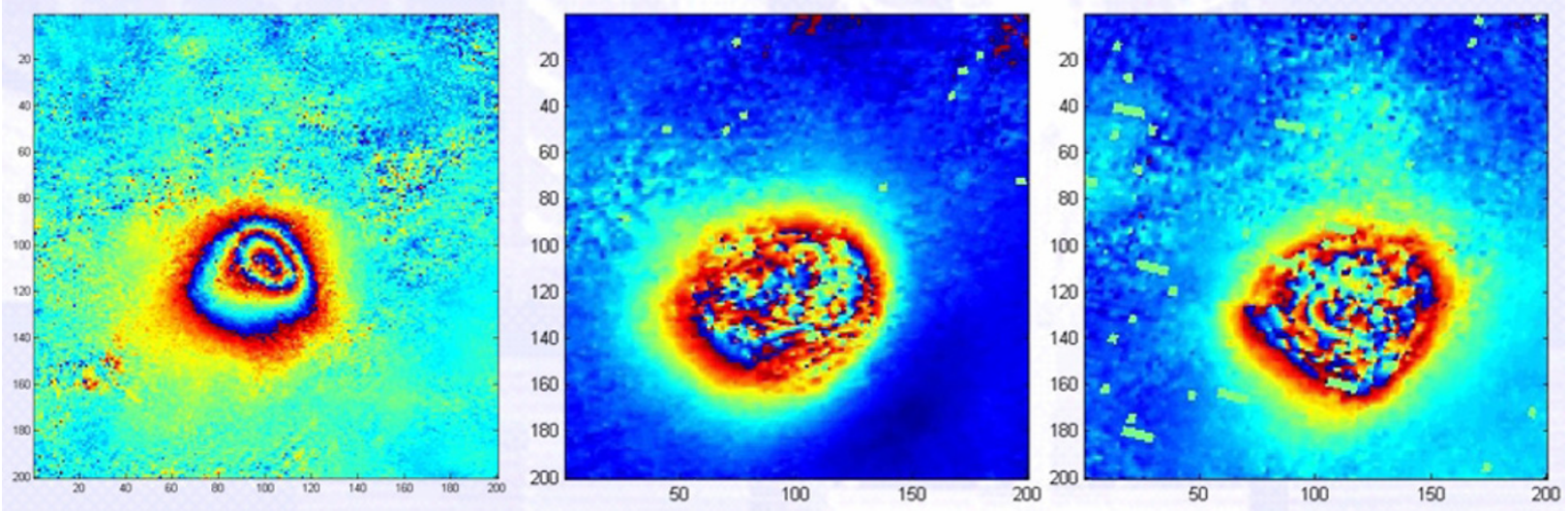

Fig. 13. Differential Interferogram generated by: (left) ALOS PALSAR data with $B_{\text {perp }}=530.4$ m, image acquisition period 27 December $2006 \sim 11$ February 2007 (46 days), ascending, incident angle $=38.7^{\circ}$; (middle) ENVISAT ASAR data with $B_{\text {perp }}=-240$ m, image acquisition period 10 December 2006 14 January 2007 (35 days), ascending, incident angle: $28.5^{\circ}$; (right) ENVISAT ASAR data with $B_{\text {perp }}=-240 \mathrm{~m}$, image acquisition period 08 December 2006 12 January 2007 (35 days), descending, incident angle: 33.9 .
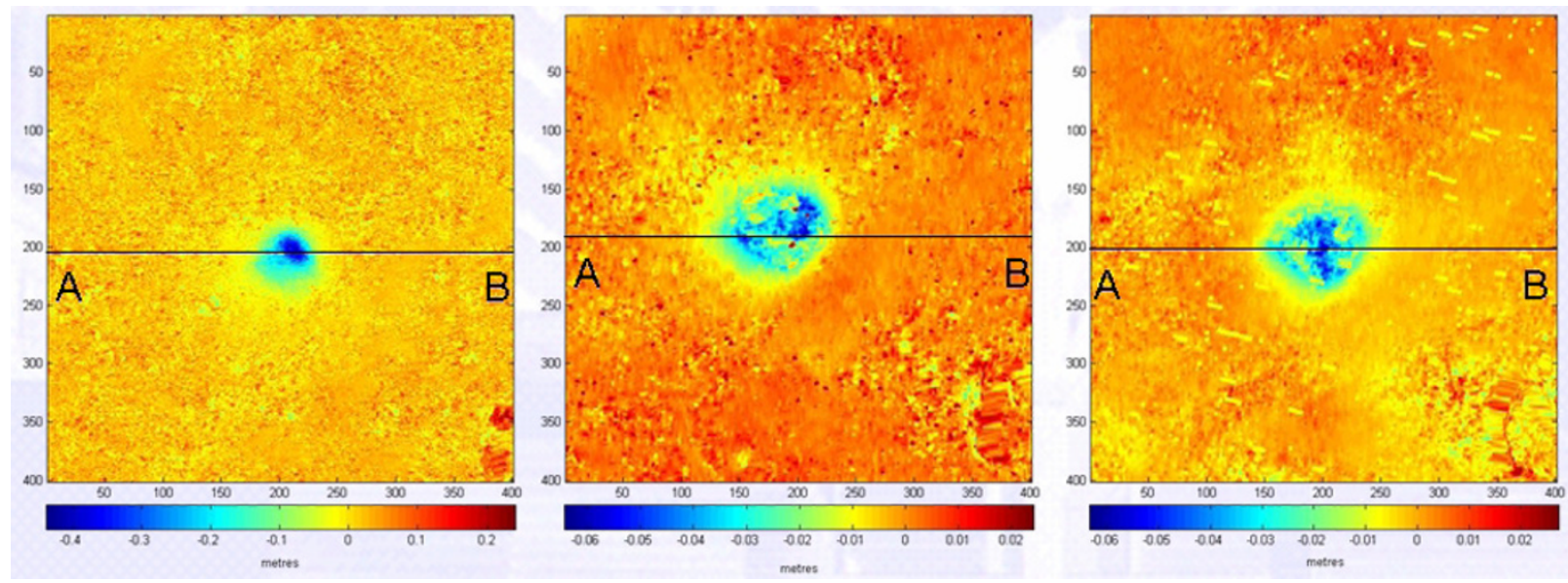

Fig. 14. Vertical displacement maps generated by: (left) ALOS PALSAR data with $B_{\text {perp }}=530.4$ m, image acquisition period 27 December $2006 \sim 11$ February 2007 (46 days), ascending, incident angle $=38.7^{\circ}$; (middle) ENVISAT ASAR data with $B_{\text {perp }}=-240$ m, image acquisition period 10 December 2006 14 January 2007 (35 days), ascending, incident angle: $28.5^{\circ}$; (right) ENVISAT ASAR data with $B_{\text {perp }}=-240 \mathrm{~m}$, image acquisition period 08 December 2006 12 January 2007 (35 days), descending, incident angle: $33.9^{\circ}$.

\subsection{Test site 1: Tahmoor}

The Tahmoor Colliery is one of the underground coalmines selected in this study to investigate the performance of DInSAR in the presence of phase discontinuities. According to the mining schedule (GeoTerra, 2006), the underground coalmine operated under a residential area from December 2006 to February 2007. The width of each longwall panel in the mine is about $300 \mathrm{~m}$ (ibid, 2006). Three differential interferograms were generated from one ascending and one descending ENVISAT ASAR pair and an ascending ALOS PALSAR pair, as shown in Fig. 13. The fringes in the differential interferogram derived from the ALOS pair are very clear and the phase can be easily unwrapped. However, interferograms derived from both ENVISAT pairs show phase saturation near the centre of the subsidence bowl, while the fringes at the rims of the subsidence bowl are reasonably clear. The interferograms in Fig. 13 are unwrapped using the MCF method, and are converted into vertical displacement (Fig. 14). A cross section of the displacement maps between A and B in Fig. 14 is computed (Fig. 15), which shows that the phases in both
ENVISAT differential interferograms are incorrectly unwrapped due to the phase saturation. The maximum subsidence both ENVISAT pairs detected from the interferograms is about $5 \mathrm{~cm}$, whereas the maximum subsidence the ALOS pair detected is about $45 \mathrm{~cm}$ (Fig. 15).

\subsection{Test site 2: Appin}

The Appin Colliery is the second underground coalmine selected for this study. Based on the mining schedule the underground mine operated under an area covered by vegetation from June 2007 to early July 2007, under an area partially covered by vegetation in mid July 2007, and under an area with very little vegetation from mid July 2007 to August 2007 (Fig. 12). By comparing the differential interferograms over the areas covered with and without vegetation it is possible to investigate the influence on multiplatform satellites with the effect of temporal decorrelation. A subsidence map is generated using an ALOS PALSAR pair and is overlaid on the ALOS PALSAR intensity image (Fig. 16(a1)) and it shows that subsidence was detected in both heavily vegetated and little vegetated areas. The area that is heavily vegetated and the little vegetated area 


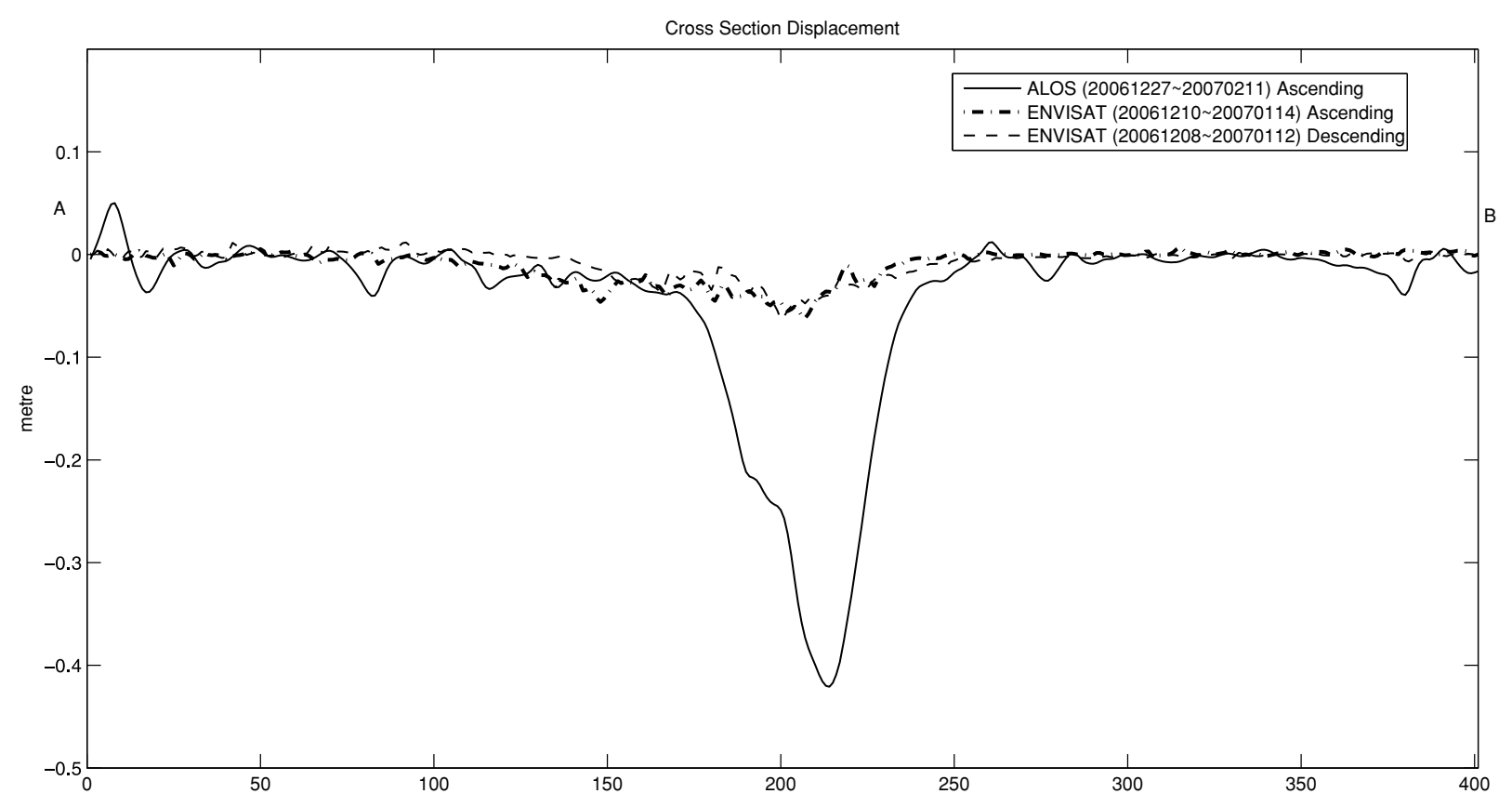

Fig. 15. Cross section of displacement maps between A and B from Fig. 14.

can be easily distinguished in the ALOS PALSAR intensity image, where the bright colour represents the heavily vegetated area and dark colour indicates area with little or no vegetation. The fringes in the differential interferogram derived from the ALOS pair are very clear and the phase can be easily unwrapped even in the heavily vegetated area (Fig. 16(a2)). A maximum subsidence of $40 \mathrm{~cm}$ has been measured at the Appin mine site for the period 29 June 2007 14 August 2007 (Fig. 16(a1)). The ENVISAT pairs acquired during a similar period are expected to show subsidence of similar magnitude. The differential interferogram generated by the ENVISAT pair shows phase saturation in the centre of the subsidence bowl (Fig. 16(b2)). Unlike Figs. 13(b) and (c), the fringes at the rim of the subsidence bowl in Appin are only clear in the upper parts of the image (low vegetation area) and are very noisy at the lower parts (heavily vegetated area) (Fig. 16(b2)). Hence ENVISAT results can be easily affected by vegetation. This can also be seen by comparing the upper subsidence bowl (Westcliff), which is not covered by heavy vegetation, and the lower subsidence bowl (Appin), which is partially covered by vegetation in Fig. 16(b2).

\section{Discussions and Conclusions}

The performance of recently launched SAR satellites for ground subsidence monitoring purposes was investigated in this study. The impact of decorrelation and phase discontinuity for mine subsidence monitoring applications could be minimised by having SAR satellite missions with longer radar wavelength, greater incident angle and finer ground imaging resolution.

Simulation studies have shown that the recently launched satellites ALOS, TerraSAR-X and COSMO-SkyMed perform much better than past SAR satellites for ground subsidence monitoring due to underground mining. X-band satellites, TerraSAR-X and COSMO-SkyMed, have demon- strated their ability to monitor ground subsidence in simulation studies where temporal decorrelation due to different terrains is not considered. The simulation results suggest that finer resolution and greater incidence angles can be used to overcome the high phase gradient. However, it is known that $\mathrm{X}$-band is very sensitive to ground vegetation, and higher temporal decorrelation is expected compared to C- and L-band systems. DEM requirements is another issue when using SAR satellites with high resolution such as TerraSAR-X and COSMO-SkyMed. A DEM with a finer resolution than the ground resolution of the satellite image is necessary to maximise the quality of the DInSAR results. Most commonly used DEMs do not have as high resolution as the ground resolution of satellites such as TerraSAR-X and COSMO-SkyMed, which is a problem for 2-pass DInSAR processing. Three-pass DInSAR processing may be required in such cases.

The analysis using real data showed that ALOS PALSAR interferometric pairs were less affected by the impact of decorrelation and phase discontinuity due to its spatial resolution and longer wavelength with respect to the wavelengths used by other SAR satellites. Hence ALOS PALSAR is preferred for ground subsidence monitoring in areas covered by vegetation and where there is a high rate ground deformation.

Ground movement or deformation may be caused by both natural disasters and anthropogenic activities. The deformation may also have various amplitudes, rates and coverage, depending on the causes. The height ambiguity of DInSAR is related to the wavelength of the radar signal used, as every $2 \pi$ phase change between two pixels in a differential interferogram is equivalent to a ground displacement at a half of the wavelength along the radar's look direction. It implies that for a shorter radar wavelength, e.g. C-band used by ENVISAT and ERS-1/2, it is more sensitive to the ground deformation than a longer wavelength, e.g. L-band 


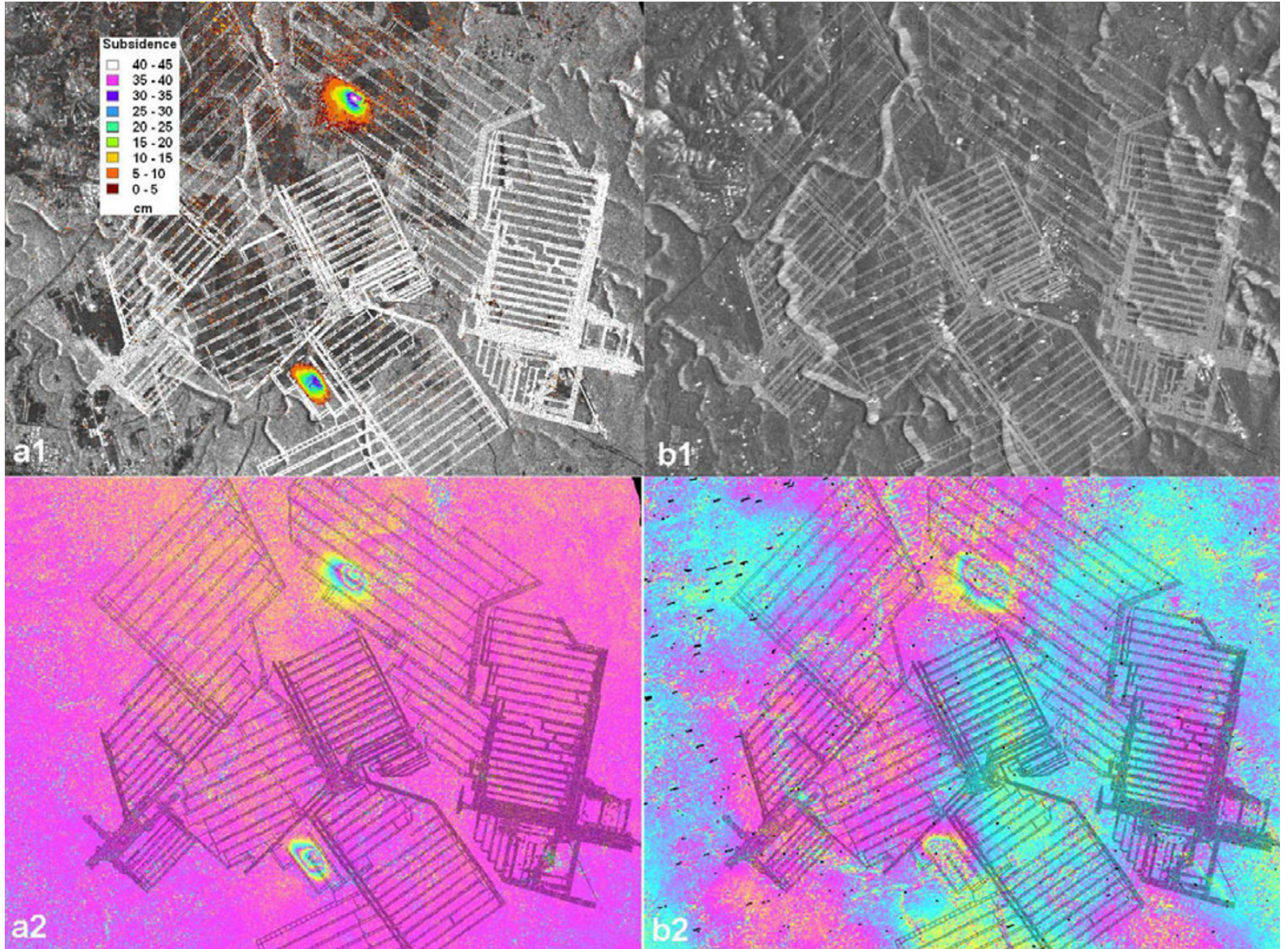

Fig. 16. (a1) Subsidence maps and (a2) differential interferogram generated by ALOS PALSAR data with $B_{\text {perp }}=44.75 \mathrm{~m}$, image acquisition period 29 June 2007 14 August 2007 (46 days), ascending, incident angle $=38.7^{\circ}$; (b1) Intensity maps and (b2) differential interferogram generated by ENVISAT ASAR data with $B_{\text {perp }}=89.94 \mathrm{~m}$, image acquisition period 05 July $2007 \sim 09$ August 2007 (35 days), ascending, incident angle $=19^{\circ}$. The upper subsidence bowl is located at the Westcliff mine site and the lower subsidence bowl is located at the Appin mine site.

used by ALOS. The measurement of ground deformation using DInSAR is restricted by the phase gradient in the interferogram. When the phase gradient in a differential interferogram is converted to ground displacement, imaging resolution, incidence angle and wavelength of the SAR system have all been taken into account. To generalise this, by assuming having the same imaging resolution and incidence angle, DInSAR with shorter radar wavelengths is more sensitive to small ground movement while system with longer radar wavelengths is more suitable for large deformation in order to avoid the phase saturation problem. Therefore SAR satellites with short wavelength may be more suitable for monitoring mine sites with low rates of ground deformation.

The subsidence caused by longwall mining technique can be very large, immediately after or during mining. It is not straight forward to measure the relationship between the satellite repeat time and the subsidence rate as the subsidence rate is non-linear. However most of the deformation due to mining activity occurs in the first 30-40 days after the coal seam is removed. Satellite with shorter repeat time should have higher successful rate for detecting the subsidence due to underground mining given that the satellite configuration is the same. This is mainly due to two reasons: 1) image pair with short time period is expected to have less temporal decorrelation; 2) the magnitude of subsidence will be less over a shorter time span, therefore, it has less chance for having phase saturation. Although shorter satellite repeat time may improve the performance for detecting mine subsidence, it is bounded to the maximum detectable phase gradient. The range of deformation rate suitable for each satellite can be estimated based on Eq. (8). Theoretically, the expected maximum deformation rate that can be detected in a differential interferogram (without phase discontinuity) is approximately $0.5 \mathrm{~mm} / \mathrm{m}$, $0.5 \mathrm{~mm} / \mathrm{m}, 3.3 \mathrm{~mm} / \mathrm{m}, 5.9 \mathrm{~mm} / \mathrm{m}, 2.6 \mathrm{~mm} / \mathrm{m}$ and $2.6 \mathrm{~mm} / \mathrm{m}$ for ERS, ENVISAT, JERS-1, ALOS, TerraSAR-X and COSMO-SkyMed satellites respectively, along the LOS direction.

More radar satellite missions are scheduled for launch in the coming years. COSMO-SkyMed-3 and 4 will be launched in 2008/2009. Four small S-band radar satellites will be launched in 2008/2009 by China; and there have been announcements of plans to deploy constellations of InSAR satellites in the future by NASA and other space agencies (Solomon et al., 2003). As a result, in a few years time radar data will be available in multiple bands, for example, X-, C-, S- and L-bands, with weekly or even daily revisit cycles. The DInSAR technique will be a cost-effective technique that is in many ways complementary to conventional 
ground surveying techniques for many deformation monitoring applications including mine-induced ground subsidence.

Acknowledgments. This research work has been supported by the Cooperative Research Centre for Spatial Information (CRCSI) Project 4.2 and currently Project 4.09, whose activities are funded by the Australian Commonwealth's Cooperative Research Centres Programme. The Australian Research Council (ARC) has been supporting DInSAR research at UNSW over a number of years. The Australian Coal Association Research Program (ACARP) has also supported research into ground subsidence monitoring using DInSAR. The authors wish to thank the European Space Agency and the Earth Remote Sensing Data Analysis Center (ERSDAC) for providing the ENVISAT ASAR and ALOS PALSAR data, respectively. METI and JAXA retain ownership of the ALOS PALSAR original data. ALOS PALSAR material copyright METI and JAXA. PALSAR L-1.1 product were produced by ERSDAC. The PALSAR L-1.1 products were distributed to the IAG Consortium for Mining Subsidence Monitoring by ERSDAC. The authors also wish to thank BHP Billiton for providing the ground survey data and other spatial data.

\section{References}

Carnec, C., D. Massonnet, and C. King, Two examples of the use of SAR interferometry on displacement fields of small spatial extent, Geophys. Res. Lett., 23(24), 3579-3582, 1996.

Chang, H. C., L. Ge, and C. Rizos, Radar interferometry for monitoring land subsidence due to underground water extraction, Spatial Sciences Conference, Melbourne, Australia, 736-743, CD-ROM procs, 12-16 September, 2005.

Chen, C. W. and H. A. Zebker, Phase unwrapping for large SAR interferograms: statistical segmentation and generalized network models, Geosci. Remote Sensing, IEEE Trans., 40(8), 1709-1719, 2002.

Costantini, M., A novel phase unwrapping method based on network programming, Geosci. Remote Sensing, IEEE Trans., 36, 813-818, 1998.

Ge, L., H. C. Chang, and C. Rizos, Satellite radar interferometry for mine subsidence monitoring, 22nd Australian Institute of Mine Surveyors Annual Seminar, Wollongong, Australia, paper 5, CD-ROM procs, $18-$ 20 August, 2004.
Ge, L., H. C. Chang, and C. Rizos, Mine subsidence monitoring using multi-source satellite SAR images, J. Photogrammetric Eng. \& Remote Sensing, 73(3), 259-266, 2007.

GeoTerra Pty Ltd., Centennial Tahmoor Longwall panels 24 to 26, Surface water \& Groundwater, subsidence management plan, Tahmoor, NSW, 80 pp., GeoTerra Pty Ltd., 2006.

Goldstein, R. M., H. Engelhardt, B. Kamb, and R. M. Frolich, Satellite radar interferometry for monitoring ice sheet motion: Application to an Antarctic ice stream, Science, 262, 1525-1530, 1993.

Hanssen, R. F., Radar Interferometry-Data Interpretation and Error Analysis, 328 pp., Kluwer Academic Publishers, 2001.

Lanari, R., P. Lundgren, and E. Sansosti, Dynamic deformation of Etna volcano observed by satellite radar interferometry, Geophys. Res. Lett., 25, 1541-1544, 1998.

Massonnet, D. and K. L. Feigl, Satellite radar interferometric map of the coseismic deformation field of the $M=6.1$ Eureka Valley, California, earthquake of May 17, 1993, Geophys. Res. Lett., 22, 1541-1544, 1995.

Nestbitt, A., Subsidence monitoring West Cliff Colliery longwall 5A4, APAS (Association of Public Authority Surveyors) 2003 Conference, Wollongong, Australia, 1-4 April, 133-139, 2003.

Nolan, M. and D. R. Fatland, New DEMs may stimulate significant advancements in remote sensing of soil moisture, Eos Trans. AGU, 84(25), 233, 2003.

Peng, Syd. S., Coal Mine Ground Control, 2nd edition, 506 pp., John Wiley \& Sons, 1986.

Schofield, W., Engineering Surveying, 554 pp., Laxton's, Oxford, UK, 1993.

Solomon, S. C., V. R. Baker, J. Bloxham, J. Booth, A. Donnellan, C. Elachi, D. Evans, E. Rignot, D. Burbank, B. F. Chao, A. Chave, A. Gillespie, T. Herring, R. Jeanloz, J. LaBrecque, B. Minster, W. C. Pitman, III, M. Simons, D. L. Turcotte, and M. L. C. Zoback, Plan for living on a restless planet sets NASA's solid Earth agenda, Eos Trans. AGU, 84(45), 485-491, 2003.

Zebker, H. A., P. A. Rosen, R. M. Goldstein, A. Gabriel, and C. L. Werner, On the derivation of coseismic displacement fields using differential radar interferometry: The Landers earthquake, J. Geophys. Res., 99(19), 19,617-19,643, 1994.

A. H.-M. Ng (e-mail: alex.ng@student.unsw.edu.au), H.-C. Chang, L. Ge, C. Rizos, and M. Omura 